\title{
Effect of Trichoderma on mycelium development of selected Agaricus bisporus (Lange) Imbach strains
}

\author{
Wpływ grzybów rodzaju Trichoderma na rozwój grzybni \\ wybranych odmian Agaricus bisporus (Lange) Imbach
}

\author{
Romuald Górski ${ }^{1}$, Krzysztof Sobieralski ${ }^{2}$, Marek Siwulski ${ }^{2}$, Iwona Sas-Golak ${ }^{2}$, Daniel Lewandowski ${ }^{2}$
}

\begin{abstract}
Summary
Effect of Trichoderma isolates on mycelium development of some strains of Agaricus bisporus was investigated. The following strains of $A$. bisporus were examined: Amycel 2000, Polmycel 22, Irlandzka 501, Sylvan 130, Le Lion X13 and Somycel 516. The Trichoderma isolates belonged to several species, i.e. T. aggressivum f. europaeum, T. atroviride, T. harzianum, T. hamatum, T. inhamatum, T. koningii and T. viride. The experiment was conducted on wheat agar medium. Based on individual biotic effect (IBE) varied interactions between Trichoderma isolates and $A$. bisporus strains were found. The obtained IBE index ranged from +2 to +8 . The highest IBE index $(+8)$ was recorded for $T$. aggressivum f. europaeum T. agg. 2/37 isolate in relation to all examined $A$. bisporus strains. The IBE index for T. harzianum T. har. $3 / 48$ and T. viride. T. vir. $4 / 29$ isolates reached the value from +5 to +6 . The IBE index for T. hamatum T. ham. $1 / 22$ isolate ranged from +3 to +4 , while for $T$. inhamatum T. inh. $5 / 32$ isolate fluctuated from +2 to +4 .
\end{abstract}

Key words: button mushroom; mycelium; strain; individual biotic effect

\section{Streszczenie}

Badano wpływ grzybów rodzaju Trichoderma na rozwój grzybni różnych odmian pieczarki dwuzarodnikowej Agaricus bisporus. Użyto następujących odmian pieczarki: Amycel 2000, Polmycel 22, Irlandzka 501, Sylvan 130, Le Lion X13, Somycel 516. Wykorzystano izolaty należące do kilku gatunków Trichoderma, tj. T. aggressivum f. europaeum, T. atroviride, T. harzianum, T. hamatum, T. inhamatum, T. koningii oraz T. viride. Doświadczenie przeprowadzono na pożywce agarowej pszennej. Na podstawie oceny indywidualnego efektu biotycznego (IEB) stwierdzono zróżnicowane oddziaływanie pomiędzy badanymi izolatami grzybów rodzaju Trichoderma oraz odmianami pieczarki. Uzyskane wartości IEB wahały się od +2 do +8 . Najwyższe wskaźniki IEB (+8) w stosunku do wszystkich porównywanych odmian pieczarki stwierdzono w przypadku izolatu T. aggressivum f. europaeum T. agg. 2/37. Wskaźnik IEB w przypadku izolatów $T$. harzianum T. har. $3 / 48$ oraz T. viride. T. vir. $4 / 29$ osiągnął wartość od +5 do +6 . Dla izolatu T. hamatum T. ham. $1 / 22$ wskaźnik IEB wahał się od +3 do +4 , a dla $T$. inhamatum $T$. inh. $5 / 32$ od +2 do +4 .

Słowa kluczowe: pieczarka; grzybnia; odmiana; indywidualny efekt biotyczny

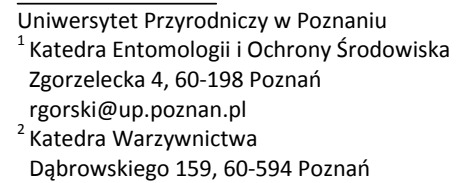




\section{Wstęp / Introduction}

Jednym z największych zagrożeń w uprawie pieczarki są grzyby rodzaju Trichoderma (Samuels i wsp. 2002; Hatvani i wsp. 2007, Kredics i wsp. 2010). Grzyby te porażają zarówno grzybnię, jak i owocniki (Hermosa i wsp. 2000; Samuels i wsp. 2002) oraz wpływają na obniżenie wielkości i jakości plonu pieczarki (Mamoun i wsp. 2000b; Savoie i wsp. 2001; Sobieralski i wsp. 2009a, 2010). Źródło zakażenia stanowi podłoże, okrywa lub grzybnia (Błażej i Tekiela 2002; Tekiela 2005; Sobieralski i wsp. 2009b). Badania przeprowadzone przez Sobieralskiego i wsp. (2010) wykazały, że izolaty Trichoderma aggressivum f. europaeum powodowały znacznie gorsze wiązanie zawiązków owocników pieczarki oraz obniżały plon.

Białe odmiany pieczarki uprawiane na podłożu zainfekowanym izolatami $T$. aggressivum f. europaeum reagowały większą obniżką plonu niż odmiany brązowe (Sobieralski i wsp. 2009a). Badania przeprowadzone W Polsce przez Błaszczyk i wsp. (2011) potwierdziły występowanie w naszym kraju licznych gatunków Trichoderma. Jak podają Szczech i wsp. (2008) w krajowych pieczarkarniach najczęściej izolowane gatunki to: T. harzianum, T. atroviride, T. longibrachiatum, T. aggressivum. W Europie Środkowej duże straty w uprawie grzybów powoduje przede wszystkim $T$. aggressivum f. europaeum (Szczech i wsp. 2008; Sobieralski i wsp. 2009b; Kosanovic i wsp. 2013). W ostatnich latach zidentyfikowano w uprawach grzybów w Japonii nowy gatunek Trichoderma - T. mienum (Kim i wsp. 2012).

Szereg gatunków grzybów rodzaju Trichoderma nie wywiera dużego wpływu na plonowanie pieczarki. Stosunkowo małą patogenicznością charakteryzują się takie gatunki, jak: T. viride, T. aureoviride, T. pseudokoningii, T. hamatum oraz T. viride (Seaby 1996; Fletcher i Gaze 2008).

Celem przeprowadzonych badań było określenie wpływu różnych izolatów grzybów rodzaju Trichoderma na rozwój grzybni kilku odmian Agaricus bisporus.

\section{Materiały i metody / Materials and methods}

W doświadczeniu użyto następujących odmian pieczarki: Amycel 2000, Polmycel 22, Irlandzka 501, Sylvan 130, Le Lion X13, Somycel 516. Izolaty różnych gatunków Trichoderma użytych w doświadczeniu podano w tabeli 1. Odmiany i szczepy, które posłużyły jako materiał doświadczalny, pochodziły z kolekcji grzybów Katedry Warzywnictwa Uniwersytetu Przyrodniczego w Poznaniu. Doświadczenie przeprowadzono na pożywce agarowej pszennej w trzech powtórzeniach.

Szczepienia dokonano na stole o laminarnym przepływie powietrza. Grzybnię grzyba testowanego i konkurencyjnego zaszczepiono na tej samej szalce Petriego w odległości $4 \mathrm{~cm}$ od siebie. Fragmenty zaszczepionej grzybni miały równą wielkość, co uzyskano posługując się rurkami plastikowymi o średnicy otworów $5 \mathrm{~mm}$. Szalki Petriego zaszczepione pożywką inkubowano w cieplarce w stałej temperaturze $25^{\circ} \mathrm{C}$, bez dostępu światła, przy wilgotności $80-85 \%$.

Codziennie dokonywano pomiarów wzrostu grzybni badanych gatunków oraz obserwacji interakcji pomiędzy rozwijającymi się grzybniami. Ustalono oceny indywidualnego efektu biotycznego (IEB) na podstawie skali stosunków biotycznych opracowanych przez Mańkę (1974) (tab. 2). Obserwacji dokonywano w zakresie: stopnia otoczenia jednej kolonii przez druga, szerokości strefy inhibicyjnej, ograniczenia wzrostu lub porażenia jednej kolonii przez drugą. Doświadczenie zakończono w momencie opanowania całej powierzchni pożywki przez rozwijające się kolonie, na każdej płytce.

Wynik interakcji między kolonią grzyba testowanego a kolonią grzyba konkurencyjnego wyraża się przez algebraiczne zsumowanie wszystkich możliwych punktów według przytoczonej skali ocen, tj. stopień otoczenia jednej kolonii przez druga, szerokość strefy inhibicyjnej, ograniczenie wzrostu. Wynik dodatni oznacza wpływ ograniczający rozwój kolonii grzyba testowanego.

Tabela 1. Charakterystyka izolatów Trichoderma sp. pochodzących z polskich pieczarkarni Table 1. Characteristics of Trichoderma sp. isolates derived from Polish mushroom farms

\begin{tabular}{|c|c|c|c|c|c|}
\hline $\begin{array}{l}\text { Lp. } \\
\text { No. }\end{array}$ & $\begin{array}{l}\text { Gatunek } \\
\text { Species }\end{array}$ & $\begin{array}{l}\text { Symbol izolatu } \\
\text { Isolate designation }\end{array}$ & $\begin{array}{l}\text { Rok uzyskania } \\
\text { izolatu } \\
\text { Year of isolate } \\
\text { collection }\end{array}$ & $\begin{array}{l}\text { Miejscowość } \\
\text { Place }\end{array}$ & $\begin{array}{c}\text { Miejsce uzyskania } \\
\text { izolatu } \\
\text { Source of isolate }\end{array}$ \\
\hline 1. & $\begin{array}{l}\text { T. aggresivum } \\
\text { f. europaeum }\end{array}$ & T. agg. $2 / 37$ & 2011 & Skierniewice & $\begin{array}{c}\text { okrywa } \\
\text { casing soil }\end{array}$ \\
\hline 2. & T. atroviride & T. at. $7 / 52$ & 2006 & Lublin & $\begin{array}{l}\text { podłoże } \\
\text { substrate }\end{array}$ \\
\hline 3. & T. harzianum & T. har. $3 / 48$ & 2007 & Poznań & $\begin{array}{l}\text { okrywa } \\
\text { casing soil }\end{array}$ \\
\hline 4 & T. hamatum & T. ham. $1 / 22$ & 2010 & Leszno & $\begin{array}{l}\text { podłoże } \\
\text { substrate }\end{array}$ \\
\hline 5. & T. inhamatum & T. inh. $5 / 32$ & 2008 & Rakoniewice & $\begin{array}{c}\text { okrywa } \\
\text { casing soil }\end{array}$ \\
\hline 6. & T. koningii & T. kon. $8 / 46$ & 2009 & Leszno & $\begin{array}{l}\text { podłoże } \\
\text { substrate }\end{array}$ \\
\hline 7. & T. viride & T. vir. $4 / 29$ & 2008 & Mosina & $\begin{array}{l}\text { okrywa } \\
\text { casing soil }\end{array}$ \\
\hline
\end{tabular}


Tabela 2. Skala ocen do ustalenia indywidualnego efektu biotycznego (IEB) według Mańki (1974)

Table 2. Score scale for the determination of individual biotic effect (IBE) (according to Mańka 1974)

Rodzaj interakcji między koloniami - Type of interaction between colonies

Obydwie kolonie stykają się wzdłuż linii prostej

Both colonies are in contact along straight line

Kolonia A styka się z kolonią B wzdłuż linii lekko krzywej tak, że otacza mniej niż 1/3 koloni A

Colony A remains in contact with colony B along slightly curved line so that it surrounds less than $1 / 3$ of colony A

Kolonia A styka się z kolonią B wzdłuż linii krzywej tak, że otacza co najmniej 1/3, ale mniej niż 1/2 koloni A

Colony A remains in contact with colony B along curved line so that it surrounds at least $1 / 3$ but less than $1 / 2$ of colony $\mathrm{A}$

Kolonia A styka się z kolonią B wzdłuż linii krzywej tak, że otacza co najmniej 1/2, ale mniej niż 2/3 koloni A

Colony A remains in contact with colony B along curved line so that it surrounds at least $1 / 2$ but less than $2 / 3$ of colony $\mathrm{A}$

Kolonia A styka się z kolonią B wzdłuż linii krzywej tak, że otacza co 2/3 albo więcej koloni A

Colony A remains in contact with colony B along curved line so that it surrounds at least $2 / 3$ or more of colony A

Każdy milimetr strefy inhibicyjnej zajęty przez kolonię A

Each millimetre of the inhibition zone is occupied by colony A

Kolonia B co najmniej o 1/3 lecz mniej niż o 1/2 mniejsza niż jej kolonia kontrolna rozwinięta indywidualnie na innej płytce Colony $\mathrm{B}$ at least by $1 / 3$ but less that $1 / 2$ smaller than its control colony developed individually on a separate plate

Kolonia B co najmniej o 2/3 mniejsza niż jej kolonia kontrolna rozwinięta indywidualnie na innej płytce

Colony $\mathrm{B}$ at least by $2 / 3$ smaller than its control colony developed individually on a separate plate

Kolonia B zupełnie nierozwinięta

Colony B completely undeveloped

Tabela 3. Indywidualny efekt biotyczny dla izolatów Trichoderma i odmian pieczarki

Table 3. Individual biotic effect index for Trichoderma isolates and A. bisporus strains

\begin{tabular}{|c|c|c|c|c|c|c|}
\hline \multirow{2}{*}{$\begin{array}{l}\text { Izolaty Trichoderma } \\
\text { Trichoderma isolates }\end{array}$} & \multicolumn{6}{|c|}{ Odmiana - Strain } \\
\hline & Amycel 2000 & Polmycel 22 & Irlandzka 501 & Sylvan 130 & Le Lion X13 & Somycel 516 \\
\hline $\begin{array}{l}\text { T. aggresivum } \\
\text { f. europaeum T. agg. 2/37 }\end{array}$ & 8 & 8 & 8 & 8 & 8 & 8 \\
\hline T. atroviride T. at. $7 / 52$ & 4 & 3 & 3 & 2 & 3 & 3 \\
\hline T. harzianum T. har. $3 / 48$ & 6 & 5 & 6 & 6 & 5 & 6 \\
\hline T. hamatum T. ham. 1/22 & 3 & 3 & 4 & 3 & 4 & 4 \\
\hline T. inhamatum T. inh. 5/32 & 3 & 2 & 3 & 2 & 2 & 3 \\
\hline T. koningii T. kon. 8/46 & 5 & 5 & 4 & 5 & 4 & 5 \\
\hline T. viride T. vir. $4 / 29$ & 6 & 5 & 5 & 5 & 6 & 5 \\
\hline
\end{tabular}

\section{Wyniki i dyskusja / Results and discussion}

$\mathrm{Na}$ podstawie oceny indywidualnego efektu biotycznego (IEB) stwierdzono wzajemne zróżnicowane oddziaływanie pomiędzy badanymi izolatami grzybów rodzaju Trichoderma oraz odmianami pieczarki (tab. 3). Wartości IEB, które uzyskano w trakcie badań, wahały się od +2 do +8 . Najwyższe wskaźniki IEB $(+8)$ w stosunku do wszystkich porównywanych odmian pieczarki stwierdzono w przypadku izolatu T. aggressivum f. europaeum T. agg. 2/37. Badania Mamoun i wsp. (2000a) wykazały, że istnieje chemiczna interakcja pomiędzy A. bisporus i $T$. aggressivum. Silne ograniczenie wzrostu i rozwoju A. bisporus przez grzyb T. aggressivum stwierdzili także Williams i wsp. (2003).

Stosunkowo wysoki wskaźnik IEB wahający się o +5 do +6 stwierdzono w przypadku izolatów $T$. harzianum T. har. 3/48 oraz T. viride T. vir. 4/29. Uzyskane wyniki nie potwierdzają wyników uzyskanych przez Seaby (1996), który zalicza m.in. T. viride do gatunków o małej patogeniczności w stosunku do pieczarki. Wskaźnik IEB dla izolatu $T$. viride był wysoki, od +5 do +6 , natomiast dla izolatu $T$. hamatum T. ham. $1 / 22$ wahał się od +3 do +4 , był więc stosunkowo niski i do pewnego stopnia zgodny ze stwierdzeniem cytowanego wyżej autora.

Najsłabszym oddziaływaniem charakteryzował się izolat $T$. inhamatum $T$. inh. 5/32, gdzie wartość wskaźnika IEB wahała sie od +2 do +3 . Jest to zgodne $\mathrm{z}$ wynikami licznych badań, w których wykazano istotne różnice pomiędzy odmianami pieczarki dwuzarodnikowej w odporności na grzyby rodzaju Trichoderma (Anderson i wsp. 2001; Chen i wsp. 2003; Sobieralski i wsp. 2009a). Uzyskane wyniki w pełni potwierdzily występowanie zróżnicowanej interakcji pomiędzy A. bisporus oraz grzybami rodzaju Trichoderma (Krupke i wsp. 2003; Savoie i Mata 2003; Williams i wsp. 2003; Largeteau i Savoie 2010).

\section{Wnioski / Conclusions}

1. Izolat T. aggressivum f. europaeum wykazał bardzo dużą agresywność w stosunku do grzybni wszystkich badanych odmian pieczarki. 
2. Stosunkowo dużą agresywność w odniesieniu do grzybni pieczarki badanych odmian wykazały izobaty T. harzianum oraz T. viride.

3. Mała agresywność w stosunku do grzybni badanych odmian wykazał izolat $T$. inhamatum oraz T. atroviride.
4. Stwierdzono zróżnicowaną interakcję pomiędzy grzybnią badanych odmian pieczarki oraz izolatami grzybów rodzaju Trichoderma.

Praca naukowa finansowana ze środków na naukę w latach 2009-2012 jako projekt badawczy nr NN310 089037.

\section{Literatura / References}

Anderson M.G., Beyer D.M., Wuest P.J. 2001. Yield comparison of hybrid Agaricus mushroom strains as a measure of resistance to Trichoderma green mold. Plant Dis. 85 (7): 731-734.

Błaszczyk L., Popiel D., Chełkowski J., Koczyk G., Samuels G.J., Sobieralski K., Siwulski M. 2011. Species diversity of Trichoderma in Poland. J. Appl. Genetics 52: 233-243.

Błażej J., Tekiela A. 2002. Występowanie grzybów pasożytniczych i konkurencyjnych dla pieczarki [Agaricus bisporus (Lange) Sing] w różnych podłożach i okrywie. Acta Sci. Pol. Hort. Cult. 1 (2): 33-41.

Chen X., Ospina-Giraldo M.D., Wilkinson V., Royse D.J., Romaine C.P. 2003. Resistance of pre- and post-epidemic strains of Agaricus bisporus to Trichoderma aggressivum f. aggressivum. Plant Dis. 87 (12): 1457-1461.

Fletcher J.T., Gaze R.H. 2008. Mushroom Pest and Disease Control. Manson Publishing Ltd, London, 192 pp.

Hatvani L., Antal Z., Manczinger L., Szekeres A., Druzhinina I.S., Kubicek C.P., Nagy A., Nagy E., Vágvölgyi C., Kredics L. 2007. Green mold diseases of Agaricus and Pleurotus spp. are caused by related but phylogenetically different Trichoderma species. Phytopathology 97: 532-537.

Hermosa M.R., Grondona I., Iturriaga E.A., Diaz-Minguez J.M., Castro C., Monte E., Garcia-Acha I. 2000. Molecular characterization and identification of biocontrol isolates of Trichoderma. Appl. Environ. Microbiol. 66: 1890-1898.

Kim C.S., Shirouzu T., Nakagari A., Sotome K., Nagasawa E., Maekawa N. 2012. Trichoderma mienium sp. nov., isolated from mushroom farms in Japan. Antonie van Leeuwenhock 102: 629-641.

Kosanovic D., Potocnik I., Duduk B., Vukojevic J., Stajic M., Rekanovic E., Milijasevic-Marcic S. 2013. Trichoderma species on Agaricus bisporus farms in Serbia and their biocontrol. Ann. Appl. Biol. 163: 218-230.

Kredics L., Garcia Jimenez L., Naeimi S., Czifra D., Urban P., Manczinger L., Vágvölgyi C., Hatvani L. 2010. A challenge to mushroom growers, the green mould disease of cultivated champignons. In: Curr. Res., Technol. Edu. Topics Appl. Microbiol. Microbial Biotechnol. (A. Mendez-Vilas, ed.). Microbiology Book Series 2 (1), Formatex, Badajoz, Spain: 295-305.

Krupke O.A., Castle A.J., Rinker D.L. 2003. The North American mushroom competitor, Trichoderma aggressivum f. aggressivum, produces antifungal compounds in mushroom compost that inhibit mycelial growth of the commercial mushroom Agaricus bisporus. Mycol. Res. 107 (12): 1467-1475.

Largeteau M.L., Savoie J.M. 2010. Microbially induced diseases of Agaricus bisporus, biochemical mechanisms and impact on commercial mushroom production. Appl. Microbiol. Biotechnol. 86: 63-73.

Mamoun M., Savoie J.M., Olivier J.M. 2000a. Interaction between the pathogen Trichoderma harzianum Th2 and Agaricus bisporus in mushroom compost. Mycologia 92: 233-240.

Mamoun M., Iapicco R., Savoie J.M., Olivier J.M. 2000b. Green mould disease in France, Trichoderma harzianum Th2 and other species causing damage on mushroom farms. Mushroom Sci. 15: 625-632.

Mańka K. 1974. Zbiorowiska grzybów jako kryterium oceny wpływu środowiska na choroby roślin. Zesz. Probl. Post. Nauk. Rol. 160: 9-23.

Samuels G.J., Dodd S.L., Gams W., Castelbury L.A., Petrini O. 2002. Trichoderma species associated with the green mold epidemic of commercially grown Agaricus bisporus. Mycologia 94 (1): 146-170.

Savoie J.M., Iapicco R., Largeteau-Mamoun M.L. 2001. Factors influencing the competitive saprophytic ability of Trichoderma harzianum Th2 in mushroom (Agaricus bisporus) compost. Mycol. Res. 105: 1348-1356.

Savoie J.M., Mata G. 2003. Trichoderma harzianum metabolites pre-adapt mushrooms to Trichoderma aggressivum antagonism. Mycologia 95 (2): 191-199.

Seaby D.A. 1996. Differentiation of Trichoderma taxa associated with mushroom production. Plant Pathol. 45: $905-912$.

Sobieralski K., Siwulski M., Frużyńska-Jóźwiak D., Górski R. 2009a. Impact of Trichoderma aggressivum f. europaeum Th2 on the yielding of Agaricus bisporus. Phytopathologia 53: 5-10.

Sobieralski K., Siwulski M., Górski R., Frużyńska-Jóźwiak D. 2009b. Porównanie rozwoju grzybni grzybów z rodzaju Trichoderma pochodzących z krajowych pieczarkarni. [Comparison of mycelium growth of Trichoderma genus fungi obtained from polish mushroom houses]. Prog. Plant Prot./Post. Ochr. Roślin 49 (2): 723-726.

Sobieralski K., Siwulski M., Frużyńska-Jóźwiak D., Górski R. 2010. Impact of infection with Trichoderma aggressivum f. europaeum isolates on carpophore setting and yielding of Agaricus bisporus. Phytopathologia 55: 35-41.

Szczech M., Staniaszek M., Habdas H., Ulinski Z., Szymański J. 2008. Trichoderma spp. - the cause of green mold on polish mushroom farms. Veg. Crops Res. Bull. 69: 105-114.

Tekiela A. 2005. Grzyby patogeniczne w uprawie pieczarki dwuzarodnikowej Agaricus bisporus (Lange) Imbach. Acta Agrobot. 58 (2): $189-196$.

Williams J., Clarkson J.M., Mills P.R., Cooper R.M. 2003. Saprotrophic and mycoparasitic components of aggressiveness of Trichoderma harzianum groups toward the commercial mushroom Agaricus bisporus. Appl. Environ. Microbiol. 69 (7): 4192-4199. 